\title{
A systematic review of patient-rated measures of radiodermatitis in breast cancer radiotherapy
}

\author{
Julie B. Schnur, PhD ${ }^{1}$, Bianca Love, BA ${ }^{1}$, Bari L. Scheckner, BA ${ }^{1}$, Sheryl Green, MD², A. \\ Gabriella Wernicke, $\mathbf{M D}^{3}$, and Guy H. Montgomery, $\mathbf{P h D}^{1}$ \\ ${ }^{1}$ Department of Oncological Sciences, Integrative Behavioral Medicine Program, Mount Sinai \\ School of Medicine, New York, NY \\ ${ }^{2}$ Department of Radiation Oncology, Mount Sinai School of Medicine, New York, NY \\ ${ }^{3}$ Department of Radiation Oncology, Weill Medical College of Cornell University, New York, NY
}

\begin{abstract}
During breast cancer radiotherapy, nearly all patients will experience radiodermatitis. Study objectives were to: 1) systematically review the literature on radiodermatitis and breast cancer; 2) summarize and describe patient-rated radiodermatitis measures; 3 ) determine whether consensus exists regarding subjective radiodermatitis measurement; and 4) provide recommendations for future research. PubMed and CINAHL were searched from their inception through August 2009. Study inclusion/exclusion criteria were: full abstract available; manuscript in English; focused on radiodermatitis resulting from breast cancer radiotherapy, and described a patient-rated empirical assessment of radiodermatitis. Three reviewers examined abstracts, and decisions about inclusion were reached by consensus. 22/237 mutually identified studies met selection criteria. Using a standardized abstraction form, three authors independently extracted relevant information. Results indicated that: 1 ) only $9 \%$ of the studies reviewed included a patient-rated measure; 2 ) generally, extant scales are very brief and focus almost exclusively on physical reactions, and 3) there is no "gold standard" measure of patient-rated radiodermatitis at this time. We conclude that significantly more research is needed to determine the best (most valid, reliable, sensitive, comprehensive) measure(s) to evaluate the experience of radiodermatitis from the patient's perspective, and that further scale development efforts are needed.
\end{abstract}

\section{Keywords}

breast neoplasms; radiodermatitis; radiotherapy; Patient Outcome Assessments

\section{Introduction}

Radiotherapy is a key element of curative breast cancer treatment, and it has been estimated that $45 \%$ of all breast cancer patients receive radiotherapy ${ }^{1}$. During the course of breast cancer radiotherapy, the vast majority of patients (74\%-100\%) will experience radiodermatitis, also referred to as skin toxicity ${ }^{2-5}$. The physical manifestations of radiodermatitis can range from faint erythema (redness, warmth, rash-like appearance), to dry desquamation (dryness, itching, peeling), to moist desquamation (moist, oozing, tender, redness and exposure of the dermis) and necrosis ${ }^{6-9}$. After the conclusion of radiotherapy, patients may experience cutaneous fibrosis, which involves changes in skin texture, skin

Corresponding Author Information: Julie B. Schnur, Ph.D., Mount Sinai School of Medicine, Department of Oncological Sciences, Box 1130, 1425 Madison Avenue, New York, NY 10029. Fax: 212-849-2566; Phone: 212-659-5644; julie.schnur@mssm.edu. 
retraction, discomfort, telangiectasia, pain, and itching ${ }^{10}$. But radiodermatitis not only affects breast skin, it also affects the breast patient herself. Qualitative research and review articles have suggested that radiodermatitis may be experienced by patients as itching, sensitivity, pain, numbness, tenderness, warmth, tingling, throbbing, tightness, heaviness, and burning 3,11 , and that skin pain may be associated with fatigue, body image disturbance, sleep problems, and emotional distress ${ }^{12,13}$. Such qualitative data suggest that in order to understand the impact of radiodermatitis on quality of life, it is critical to assess not only the occurrence of skin reactions, but also patients' subjective experience of such reactions ${ }^{14}$.

Unfortunately, there has been a paucity of research focused on the patient's experience of radiodermatitis, including the degree to which radiodermatitis impairs quality of life (QOL) ${ }^{15}$, causes pain ${ }^{16}$, or causes distress ${ }^{15}$. Indeed, in regard to radiodermatitis, "rarely have studies considered patient comfort of primary importance" (p. E9, ${ }^{12}$ ). Overall, the effects of radiation-related skin reactions on quality of life are "largely absent in the literature" (p. E11 ${ }^{12}$ ). This lack of attention to the patient's subjective experience is inconsistent with the emphasis placed on QOL by major health organizations (World Health Organization ${ }^{17}$, Institute of Medicine ${ }^{18,19}$ ), as well as with the more widespread recognition of the need to assess patient-rated symptoms in addition to observer-rated measures (e.g., 14, 20-22).

The lack of research on the patient's subjective experience of radiodermatitis is problematic for at least four reasons. First, two people with the same observer-rated level of radiodermatitis (e.g., with the same Radiation Therapy Oncology Group (RTOG) score ${ }^{6}$ ) may have very different subjective experiences. As Schmuth et al. ${ }^{23}$ have noted (p. 987), "Clinical judgment and bioengineering techniques alone cannot reflect the potential impact of a skin condition on patients' lives." Second, if not inquired about, important symptoms (e.g., pain, impaired body image, impaired functioning) may go unrecognized and unmanaged, potentially leading to impaired patient quality of life, poor treatment satisfaction, and social constraints ${ }^{24}$ in the doctor-patient relationship. Third, breast cancer patients cannot make fully informed treatment decisions (i.e., whether or not to undergo radiotherapy) without data on how the treatment may affect their quality of life ${ }^{14}$. Fourth, if patients are not provided with accurate information about radiotherapy side effects it can inhibit their ability to cope with, understand and interpret their treatment experience; increase feelings of uncertainty; and hinder problem solving ${ }^{3}$.

It has been suggested that research on radiodermatitis has been hampered by the absence of a widely accepted and psychometrically sound scale to assess skin reactions ${ }^{4,11}$. Although there exist a number of commonly used and well-accepted observer-rated methods of evaluating radiodermatitis (e.g., ${ }^{6} ;{ }^{25}$ ), as well as more technological approaches (e.g., reflectance spectroscopy), the patient's experiences of symptoms and quality of life have been given less attention ${ }^{4}$. In 1999, Noble-Adams ${ }^{11}$ reviewed the literature on assessment of radiation-induced skin reactions in general (not focused on breast), and found that the most common assessment method at the time for radiodermatitis was physician-rated visual observation scales, and that there existed no scale at the time that could be used to assess the subjective symptoms of radiotherapy-induced skin reactions ${ }^{26}$. The goal of the present paper is to: 1) provide an up-to-date systematic review of the literature on radiodermatitis and breast cancer in order to learn which patient-rated instruments have been used to assess subjective radiodermatitis; 2) summarize and describe patient-rated radiodermatitis measures to inform future research efforts; 3 ) determine whether consensus exists regarding subjective radiodermatitis measurement; and 4) to provide recommendations for the use of current instruments as well as for future scale development in this area. 


\section{Method}

The QUORUM checklist ${ }^{27}$ guided the conduct and reporting of this systematic review.

\section{Data Sources and Search strategy}

Two electronic databases, PubMed and CINAHL were searched from their respective inceptions through August 19, 2009.

For PubMed, the search terms were: "Radiodermatitis"[Mesh] AND ("Breast Neoplasms"[Mesh] OR breast). Limits placed on the search required articles to be about humans and in English. This search yielded 202 abstracts/titles.

For CINAHL, the search terms were: ("breast neoplasms" or "breast") AND radiodermatitis. The only limit placed on the search was that the article had to be in English. This search yielded 35 abstracts/titles.

\section{Study Selection Strategy}

The abstracts/titles of all articles identified by electronic searches (237 in total) were carefully screened by three of the authors to determine whether they met the following inclusion criteria: (a) full abstract available online; (b) manuscript written in English; (c) focused on or included breast cancer patients; (d) focused on radiotherapy for the treatment of breast cancer (e.g., not other types of radiation); (e) focused on radiodermatitis resulting from radiotherapy; (f) described a patient-rated empirical assessment of radiodermatitis (e.g., excluded qualitative studies and other-rated measures); and (g) the study was not a duplicate (i.e., if an article was cited in both PubMed and CINAHL, it was only used once).

Subsequent to abstract review, 46 manuscripts were obtained and read in full, independently by three co-authors, each of whom completed a standardized form assessing the inclusion criteria. These co-authors then met together to review these 46 manuscripts. Based on consensus review by these reviewers, 22 of those 46 mutually identified studies met selection criteria and were included in the meta-analysis. Reasons for exclusion are identified in Figure 1 - QUORUM ${ }^{27}$ Flow Chart.

\section{Data Extraction and Study Characteristics}

For each of the 22 papers included in the review, relevant data was extracted independently by three of the authors using a standardized worksheet. Specifically, the standardized worksheet was used to collect the following information: authors, publication year, sample size, type of study (e.g., intervention study, descriptive study, scale development study), type of radiation received, scale name (if provided), number of scale items related to radiodermatitis, constructs measured, item rating method, and frequency of administration. Any discrepancies were discussed among the authors with reference to the original manuscript until consensus was reached.

It should be noted that: a) if a given paper reported both subjective and objective data (e.g., patient-rated and physician-rated), we focused only on the assessment items specifically identified as patient-rated or subjective; $b$ ) if a given paper reported on both quantitative and qualitative data, we only report on the quantitative data. Although both are critical pieces of information, the goal of the present review is to survey empirical measures of subjective radiodermatitis which could be used in future research; c) if a given paper had a mixed cancer sample, we only report on the breast cancer patients; and d) only questions/ questionnaires pertaining to skin reactions and related quality of life were included. Other types of questions (e.g., opinions about interventions, adverse effects related to creams 
under investigation, skin products used) are not reported on in the present review. Again, this decision was made in the interest of compiling questions/measures which could be used in clinical settings and across radiodermatitis studies (e.g., intervention studies, longitudinal studies, etc) in breast cancer.

\section{Results}

\section{Description of Trial, Sample, and Intervention Characteristics}

Table 1 presents the chief characteristics of each study and scale. The papers were published between 1979 and 2009. Sample size ranged from 2 to 331, with 12/22 having fewer than 50 breast patients, $2 / 22$ having 50-100 breast patients, $3 / 22$ having 100-200 breast patients, and $5 / 22$ having greater than 200 breast patients. Three of the studies did not report the specific type of radiation patients received; the rest involved external beam radiation. None was specifically focused on alternative forms of radiation treatment (e.g., accelerated hypofractionated radiation regimens, partial breast irradiation, etc.). The majority of the studies (86\%) were intervention studies (testing the effectiveness of various creams, homeopathic treatments, mechanical massage, behavioral strategies). Only one ${ }^{4}$ was specifically focused on the development and validation of a radiodermatitis scale. The vast majority of the studies focused on acute toxicity. Only $5 / 22$ papers reported ethnicity data on participants, and of those 5 , all were greater than $85 \%$ White.

\section{Data synthesis and Description of Scale Characteristics}

The primary finding is that only $9 \%$ of the abstracts reviewed included any patient-rated measure. In other words, $91 \%$ of the studies of radiodermatitis in breast cancer patients did not ask patients about their symptom experience. The papers which did meet inclusion criteria discussed 28 measures (some of which were single item measures). The depth of the description of the measures varied greatly between manuscripts. In some manuscripts measures are described in great detail, whereas in others the description is limited to one sentence, making data synthesis difficult. However, based on our consensus reading of the manuscripts, the results are as follows.

Tremendous heterogeneity was noted both in terms of scales used and items assessed. For example, none of the previously developed, psychometrically sound scales included in these papers (e.g., Skin Toxicity Assessment Tool, Spitzer quality of life, Radiation-Induced Skin Reaction Assessment Scale, EORTC C-30 general module or BR-23 breast cancer-specific module, Skindex, SF-36, or Dermatology quality of life index) was used more than once. Furthermore, the only scales that did appear to be used more than once were pain visual analog scales $(\mathrm{k}=4)$ and symptom diary cards $(\mathrm{k}=3)$. However, because only 1 of the 4 pain visual analog scales reported their numerical and verbal anchors, we cannot be sure that these four VASs are identical. In general, the data suggest that there currently exists no clear consensus in the field in terms of measuring patient-rated radiodermatitis.

Heterogeneity was also noted in terms of specific items assessed (see Table 1, Constructs Measured). This suggests that there is no well-accepted definition of the construct of "radiodermatitis" from the patient perspective. Every study is, in effect, measuring its own version of radiodermatitis. For one study it may mean cosmesis, for another pain, for another, more comprehensive effects on quality of life. This diversity further makes it difficult to compare across studies, and to build a knowledge base in this area.

Yet despite the heterogeneity, the following trends became apparent: 1) The vast majority of the 28 scales were extremely brief. $79 \%$ were between 1 and 5 items. 2) The most commonly asked items were erythema/redness, desquamation/peeling, burning, itching, and pain. 3) Regarding dimensions of quality of life assessed, more than half (61\%) focused 
solely on physical well-being. A smaller subset of studies looked at both physical well-being and functional well-being (25\%). However, other domains of QOL were more rarely examined, and only $11 \%$ took a more comprehensive approach (i.e., 3 or more domains of quality of life assessed) to examining radiodermatitis effects on multiple domains of quality of life $15,23,28$. 4) Clear empirical data describing scale properties (e.g., reliability, validity, time to complete, reading level) was largely absent.

\section{Discussion}

This systematic review of the literature on patient-rated measures of radiodermatitis in breast cancer radiotherapy provides an important snapshot of the current state of research in this area, and revealed at least five important areas for future growth.

Our primary finding was that out of 237 abstracts/titles reviewed, only 9\% actually asked breast cancer patients about their experience of radiodermatitis. In other words, in studies of radiodermatitis, an extremely common treatment side effect, the patient's experience, perceptions, suffering, and evaluations have generally been ignored by the breast radiotherapy research literature. These results are quite similar to findings by Noble-Adams from a decade ago ${ }^{11}$, and disappointingly suggest that little progress has been made in this area. It seems impossible to comprehensively evaluate the success or failure of any new radiotherapy technique, or any new symptom control intervention, without assessing whether patients themselves are more comfortable, are more satisfied with their appearance, feel less pain, are more satisfied with the texture of the breast, sleep better, or are more satisfied with treatment. Of course we recognize that clinically, radiotherapy treatment teams discuss these issues extensively with patients. However, if these factors are not regularly assessed in research enterprises, treatment guidelines may be decided upon without true consideration of the patient experience and without empirical data. In consequence, it is our recommendation that all future prospective research on radiotherapy-induced skin changes in breast cancer patients include at least one patient-rated measure. This will ensure that quality of life is not ignored in this population.

Second, we noted that among those studies which did measure patient-rated radiodermatitis, there was no clear agreement on which scale to use and little consistency regarding items assessed. The high variability in assessment approaches is problematic, and makes it difficult to develop norms or compare results across studies ${ }^{28}$. Moreover, the variability suggests a lack of consensus not merely in terms of measurement, but in also terms of a clear definition of the construct of patient-rated radiodermatitis. Our own qualitative work ${ }^{13}$ suggests that in order to comprehensively account for patient experiences, a patient-rated skin toxicity measure should at minimum include items about: a) nociceptive/tactile effects (e.g., pain/discomfort, burning/heat, itching, tingling, pulling and heaviness, skin texture); b) body image and satisfaction with skin color changes and skin texture; c) emotional reactions; d) functional impairment (e.g., clothing/bra changes, sleep impairment, work performance); and e) satisfaction with radiotherapy. Our general recommendation is that more work (both quantitative and qualitative) be conducted to develop an operational definition of radiodermatitis that accurately represents patients' experiences and voices.

Third, we found that the scales in use were generally quite brief and limited in scope, and focused almost exclusively on one particular aspect of quality of life - physical well-being. To address this limitation, we suggest that future research regularly address multiple dimensions of quality of life. Among the scales already in use, the most comprehensive are the Skindex, EORTC, SF-36, and DLQI. However, Wells et al. ${ }^{15}$ raised some concerns about the sensitivity of the DLQI, and more work is needed to determine the appropriateness of each of these measures in the breast cancer radiotherapy setting. More broadly, we 
recommend that significantly more research be conducted to develop a new, comprehensive, radiodermatitis scale for breast cancer patients which is informed by qualitative research as well as expert opinions. It should be noted that we recognize that skin toxicity scales may exist, or may be used more frequently, in radiotherapy populations other than breast. However, without sufficient testing and validation in breast samples, it is unclear whether they are appropriate for this population.

Fourth, we strongly recommend that more attention (i.e., better reporting) be given to descriptions of the scales, including description of supporting literature, wording/anchors, number of items, and psychometric properties. Without such knowledge, it is difficult to interpret the quality of the data collected ${ }^{14}$, and difficult to make informed decisions about using the scale in future research. Consequently, we recommend that psychometric properties of the scales be included in research reports on patient-rated radiodermatitis, and that in the future, research focus on the development and use of psychometrically reliable and valid scales.

Fifth, of those studies which did report ethnicity, samples were predominantly White. In order to determine the appropriateness of these measures across ethnic groups, future research should include more diverse samples of patients.

Of course, like any study, the present review has its limitations. First, the search strategy was focused. The Mesh term "radiodermatitis" was the descriptor used to search for radiotherapy-related skin toxicity. However, different search terms could lead to different results. As a check on our search strategy, we examined two recent reviews in the area 29,30 . Out of the 38 studies included in these reviews, only three additional studies ${ }^{31-33}$ would have met our inclusion criteria, and none of these three papers included a scale which was not already reported on in Table 1. More specifically, one used a visual analog scale and the other two rated itching/pain as none, mild, moderate, or severe. Thus, the information provided by these additional manuscripts does not change the conclusions of the present review, that the field lacks a "gold standard" patient-rated self-report measure of skin changes associated with breast cancer radiotherapy. Second, the present review included two databases - PubMed and CINAHL, and was limited to published manuscripts in English. It is possible that additional relevant papers exist outside of the present sample of papers. Future work may wish to include more languages, include unpublished manuscripts, and use a wider variety of search terms to confirm the generalizability of the present conclusions. Third, we chose not to conduct quality appraisals of the included studies, as is suggested in the QUORUM ${ }^{27}$ guidelines. We chose not to do this because we were focused on the quality of the measures, rather than the overall quality of the studies in which a measure was used. We view study quality and measure quality as separate issues. Future research may wish to rate both study and measure quality to be used as covariates in meta-analytic approaches.

In conclusion, this review suggests that although some important efforts have been made to assess breast cancer patients' experiences of radiodermatitis, the literature in this area is relatively underdeveloped compared to the literature on other cancer-related symptoms, side effects, and quality of life (e.g., ${ }^{20,21,34-36}$ ). With regard to radiodermatitis, it has been stated that $\left({ }^{11}\right.$, p. 1140), "Accurate assessment of both the subjective symptoms and the observable signs of these reactions is a prerequisite in enabling an understanding of the phenomenon and planning appropriate care. Until a holistic, valid and reliable tool is developed the concept cannot be fully examined." It is our hope that the present review will spur development of such a tool, and focus attention on the patient experience. 


\section{Acknowledgments}

Sources of support: The project described was supported by Award Number K07CA131473 from the National Cancer Institute and by RSGPB-04-213-01 from the American Cancer Society. The content is solely the responsibility of the authors and does not necessarily represent the official views of the National Cancer Institute, the National Institutes of Health, or the American Cancer Society.

\section{References}

1. National Cancer Database (NCDB) / Commission on Cancer (CoC) - NCDB Hospital Comparison Benchmark Reports [database online]. Chicago, IL: American College of Surgeons; 2006.

2. Wengstrom Y, Haggmark C, Strander H, Forsberg C. Perceived symptoms and quality of life in women with breast cancer receiving radiation therapy. Eur J Oncol Nurs. 2000; 4(2):78-88. [PubMed: 12849634]

3. Knobf MT, Sun Y. A longitudinal study of symptoms and self-care activities in women treated with primary radiotherapy for breast cancer. Cancer Nurs. 2005; 28(3):210-218. [PubMed: 15915066]

4. Berthelet E, Truong PT, Musso K, et al. Preliminary reliability and validity testing of a new Skin Toxicity Assessment Tool (STAT) in breast cancer patients undergoing radiotherapy. Am J Clin Oncol. 2004; 27(6):626-631. [PubMed: 15577442]

5. Freedman GM, Li T, Nicolaou N, Chen Y, Ma CC, Anderson PR. Breast intensity-modulated radiation therapy reduces time spent with acute dermatitis for women of all breast sizes during radiation. Int J Radiat Oncol Biol Phys. 2009; 74(3):689-694. [PubMed: 19362779]

6. Cox JD, Stetz J, Pajak TF. Toxicity criteria of the Radiation Therapy Oncology Group (RTOG) and the European Organization for Research and Treatment of Cancer (EORTC). Int J Radiat Oncol Biol Phys. 1995; 31(5):1341-1346. [PubMed: 7713792]

7. Harper JL, Franklin LE, Jenrette JM, Aguero EG. Skin toxicity during breast irradiation: pathophysiology and management. South Med J. 2004; 97(10):989-993. [PubMed: 15558927]

8. Mendelsohn FA, Divino CM, Reis ED, Kerstein MD. Wound care after radiation therapy. Adv Skin Wound Care. 2002; 15(5):216-224. [PubMed: 12368711]

9. McQuestion M. Evidence-based skin care management in radiation therapy. Semin Oncol Nurs. 2006; 22(3):163-173. [PubMed: 16893745]

10. Bourgeois JF, Gourgou S, Kramar A, Lagarde JM, Guillot B. A randomized, prospective study using the LPG technique in treating radiation-induced skin fibrosis: clinical and profilometric analysis. Skin Res Technol. 2008; 14(1):71-76. [PubMed: 18211604]

11. Noble-Adams R. Radiation-induced reactions. 1: An examination of the phenomenon. Br J Nurs. 1999; 8(17):1134-1140. [PubMed: 10897695]

12. MacBride SK, Wells ME, Hornsby C, Sharp L, Finnila K, Downie L. A case study to evaluate a new soft silicone dressing, Mepilex Lite, for patients with radiation skin reactions. Cancer Nurs. 2008; 31(1):E8-E14. [PubMed: 18176123]

13. Schnur JB, Ouellette SC, DiLorenzo TA, Green S, Montgomery GH. A qualitative analysis of skin toxicity among breast cancer radiotherapy patients. Psychooncology. 2010 Mar 17. [Epub ahead of print].

14. Kuroi K, Shimozuma K, Ohsumi S, Imai H, Ono M. Current status of health outcome assessment of medical treatment in breast cancer. Breast Cancer. 2007; 14(1):74-80. [PubMed: 17244999]

15. Wells M, Macmillan M, Raab G, et al. Does aqueous or sucralfate cream affect the severity of erythematous radiation skin reactions? A randomised controlled trial. Radiother Oncol. 2004; 73(2):153-162. [PubMed: 15542162]

16. Delaney G, Fisher R, Hook C, Barton M. Sucralfate cream in the management of moist desquamation during radiotherapy. Australas Radiol. 1997; 41(3):270-275. [PubMed: 9293679]

17. World Health Organization. [Accessed March 19, 2010] Constitution of the World Health Organization. Available at: http://www.who.int/governance/eb/who_constitution_en.pdf

18. National Cancer Policy Board, Institute of Medicine. Meeting Psychosocial Needs of Women with Breast Cancer. Washington, D.C.: National Academies Press; 2004. 
19. National Cancer Policy Board, Institute of Medicine and National Research Council. Ensuring Quality Cancer Care. Washington, D.C.: The National Academies Press; 1999.

20. Lipscomb, J.; Gotay, CC.; Snyder, C. Outcomes assessment in cancer: measures, methods and applications. New York: Cambridge University Press; 2005.

21. Perry S, Kowalski TL, Chang CH. Quality of life assessment in women with breast cancer: benefits, acceptability and utilization. Health Qual Life Outcomes. 2007; 5:24. [PubMed: 17474993]

22. Cella D, Wagner L, Cashy J, Hensing TA, Yount S, Lilenbaum RC. Should health-related quality of life be measured in cancer symptom management clinical trials? Lessons learned using the functional assessment of cancer therapy. J Natl Cancer Inst Monogr. 2007; (37):53-60. [PubMed: 17951232]

23. Schmuth M, Wimmer MA, Hofer S, et al. Topical corticosteroid therapy for acute radiation dermatitis: a prospective, randomized, double-blind study. Br J Dermatol. 2002; 146(6):983-991. [PubMed: 12072066]

24. Lepore SJ, Helgeson VS. Social constraints, intrusive thoughts, and mental health after prostate cancer. J Soc Clin Psychol. 1998; 17(1):89-106.

25. Cancer Therapy Evaluation Program (CTEP) of the National Cancer Institute (NCI). Common Terminology Criteria for Adverse Events (CTCAE): Version 4.0. U.S. Department of Health and Human Services, National Institutes of Health, National Cancer Institute; Published: May 28, 2009 (v4.02:Sept. 15, 2009)

26. Noble-Adams R. Radiation-induced skin reactions. 2: Development of a measurement tool. Br J Nurs. 1999 Oct 14; 8(18):1208-1211. [PubMed: 10897708]

27. Moher D, Cook DJ, Eastwood S, Olkin I, Rennie D, Stroup DF. Improving the quality of reports of meta-analyses of randomised controlled trials: the QUOROM statement. Quality of Reporting of Meta-analyses. Lancet. 1999; 354(9193):1896-1900. [PubMed: 10584742]

28. Pignol JP, Olivotto I, Rakovitch E, et al. A multicenter randomized trial of breast intensitymodulated radiation therapy to reduce acute radiation dermatitis. J Clin Oncol. 2008; 26(13):20852092. [PubMed: 18285602]

29. Bolderston A, Lloyd NS, Wong RK, Holden L, Robb-Blenderman L. The prevention and management of acute skin reactions related to radiation therapy: a systematic review and practice guideline. Support Care Cancer. 2006; 14(8):802-817. [PubMed: 16758176]

30. Kedge EM. A systematic review to investigate the effectiveness and acceptability of interventions for moist desquamation in radiotherapy patients. Radiography. 2009; 15:247-257.

31. Roy I, Fortin A, Larochelle M. The impact of skin washing with water and soap during breast irradiation: a randomized study. Radiother Oncol. 2001; 58(3):333-339. [PubMed: 11230896]

32. Campbell IR, Illingworth MH. Can patients wash during radiotherapy to the breast or chest wall? A randomized controlled trial. Clin Oncol (R Coll Radiol). 1992; 4(2):78-82. [PubMed: 1554631]

33. Lokkevik E, Skovlund E, Reitan JB, Hannisdal E, Tanum G. Skin treatment with bepanthen cream versus no cream during radiotherapy--a randomized controlled trial. Acta Oncol. 1996; 35(8): 1021-1026. [PubMed: 9023388]

34. Minton O, Stone P. A systematic review of the scales used for the measurement of cancer-related fatigue (CRF). Ann Oncol. 2009; 20(1):17-25. [PubMed: 18678767]

35. Kirkova J, Davis MP, Walsh D, et al. Cancer symptom assessment instruments: a systematic review. J Clin Oncol. 2006; 24(9):1459-1473. [PubMed: 16549841]

36. Hjermstad MJ, Fainsinger R, Kaasa S. Assessment and classification of cancer pain. Curr Opin Support Palliat Care. 2009; 3(1):24-30. [PubMed: 19365158]

37. Bennett C. An investigation into the use of a non-metallic deodorant during radiotherapy treatment: a randomised controlled trial. J Radiother Pract. 2009; 8:3-9.

38. Glees JP, Mameghan-Zadeh H, Sparkes CG. Effectiveness of topical steroids in the control of radiation dermatitis: a randomised trial using $1 \%$ hydrocortisone cream and $0.05 \%$ clobetasone butyrate (Eumovate). Clin Radiol. 1979; 30(4):397-403. [PubMed: 380872]

39. Graham P, Browne L, Capp A, et al. Randomized, paired comparison of No-Sting Barrier Film versus sorbolene cream (10\% glycerine) skin care during postmastectomy irradiation. Int J Radiat Oncol Biol Phys. 2004; 58(1):241-246. [PubMed: 14697444] 
40. Halyard MY, McCombs KE, Wong WW, et al. Acute and chronic results of adjuvant radiotherapy after mastectomy and Transverse Rectus Abdominis Myocutaneous (TRAM) flap reconstruction for breast cancer. Am J Clin Oncol. 2004; 27(4):389-394. [PubMed: 15289733]

41. Heggie S, Bryant GP, Tripcony L, et al. A Phase III study on the efficacy of topical aloe vera gel on irradiated breast tissue. Cancer Nurs. 2002; 25(6):442-451. [PubMed: 12464836]

42. Dische S, Warburton MF, Jones D, Lartigau E. The recording of morbidity related to radiotherapy. Radiother Oncol. 1989; 16(2):103-108. [PubMed: 2595009]

43. Macmillan MS, Wells M, MacBride S, Raab GM, Munro A, MacDougall H. Randomized comparison of dry dressings versus hydrogel in management of radiation-induced moist desquamation. Int J Radiat Oncol Biol Phys. 2007; 68(3):864-872. [PubMed: 17363185]

44. Pommier P, Gomez F, Sunyach MP, D'Hombres A, Carrie C, Montbarbon X. Phase III randomized trial of Calendula officinalis compared with trolamine for the prevention of acute dermatitis during irradiation for breast cancer. J Clin Oncol. 2004; 22(8):1447-1453. [PubMed: 15084618]

45. Porock D, Kristjanson L. Skin reactions during radiotherapy for breast cancer: the use and impact of topical agents and dressings. Eur J Cancer Care (Engl ). 1999; 8(3):143-153. [PubMed: 10763645]

46. Primavera G, Carrera M, Berardesca E, Pinnaro P, Messina M, Arcangeli G. A double-blind, vehicle-controlled clinical study to evaluate the efficacy of MAS065D (XClair), a hyaluronic acidbased formulation, in the management of radiation-induced dermatitis. Cutan Ocul Toxicol. 2006; 25(3):165-171. [PubMed: 16980242]

47. Roper B, Kaisig D, Auer F, Mergen E, Molls M. Theta-Cream versus Bepanthol lotion in breast cancer patients under radiotherapy. A new prophylactic agent in skin care? Strahlenther Onkol. 2004 May; 180(5):315-322. [PubMed: 15127162]

48. Schlappack O. Homeopathic treatment of radiation-induced itching in breast cancer patients. A prospective observational study. Homeopathy. 2004; 93(4):210-215. [PubMed: 15532701]

49. Chren MM, Lasek RJ, Quinn LM, Mostow EN, Zyzanski SJ. Skindex, a quality-of-life measure for patients with skin disease: reliability, validity, and responsiveness. J Invest Dermatol. 1996; 107(5):707-713. [PubMed: 8875954]

50. Schnur JB, Montgomery GH. Hypnosis and cognitive-behavioral therapy during breast cancer radiotherapy: a case report. Am J Clin Hypn. 2008; 50(3):209-215. [PubMed: 18246853]

51. Szumacher E, Wighton A, Franssen E, et al. Phase II study assessing the effectiveness of Biafine cream as a prophylactic agent for radiation-induced acute skin toxicity to the breast in women undergoing radiotherapy with concomitant CMF chemotherapy. Int J Radiat Oncol Biol Phys. 2001; 51(1):81-86. [PubMed: 11516855]

52. Finlay AY, Khan GK. Dermatology Life Quality Index (DLQI)--a simple practical measure for routine clinical use. Clin Exp Dermatol. 1994; 19(3):210-216. [PubMed: 8033378]

53. Lewis V, Finlay AY. 10 years experience of the Dermatology Life Quality Index (DLQI). J Investig Dermatol Symp Proc. 2004; 9(2):169-180.

54. Williams MS, Burk M, Loprinzi CL, et al. Phase III double-blind evaluation of an aloe vera gel as a prophylactic agent for radiation-induced skin toxicity. Int J Radiat Oncol Biol Phys. 1996; 36(2): 345-349. [PubMed: 8892458] 


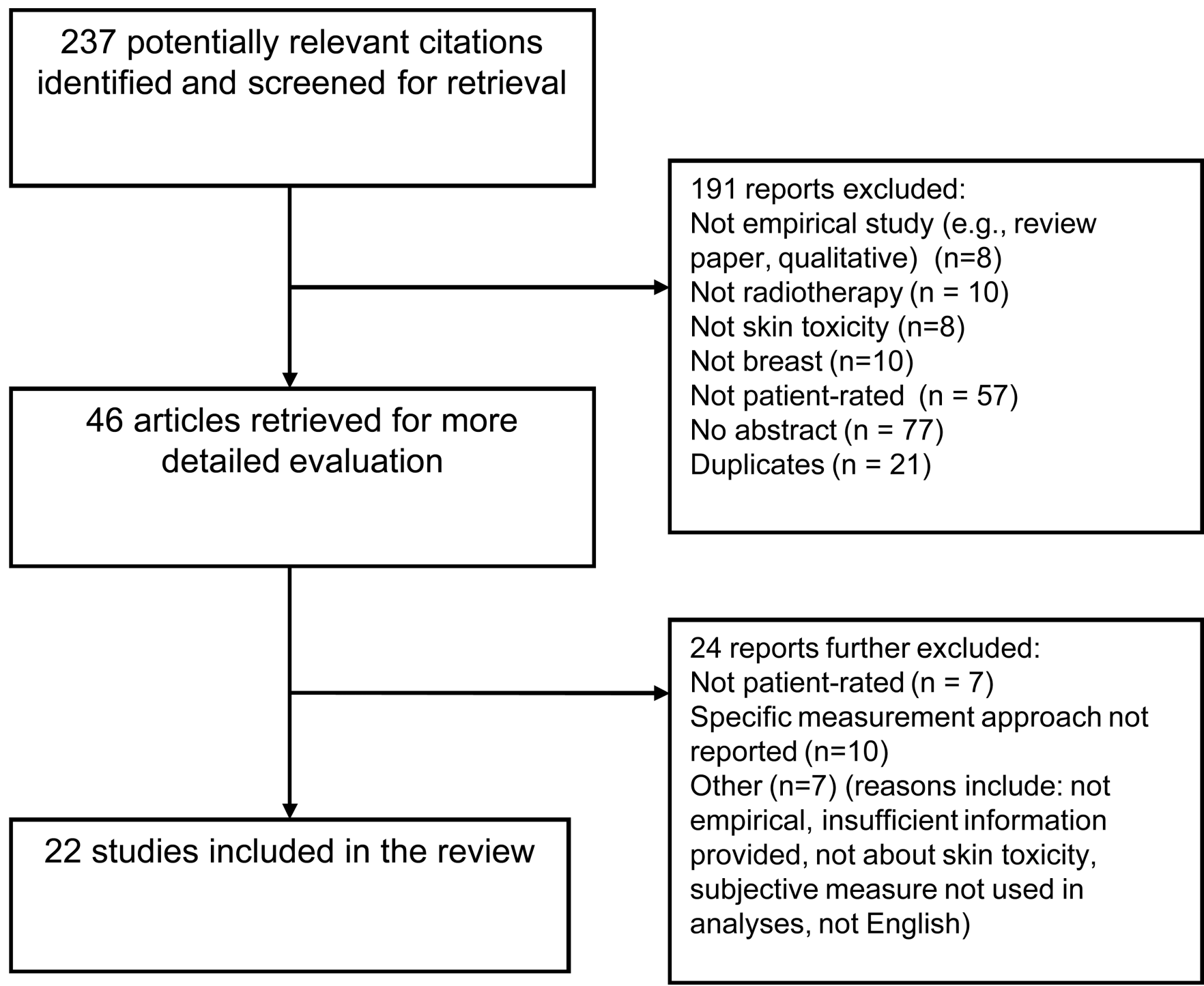

Figure 1.

QUORUM Flow Chart. 


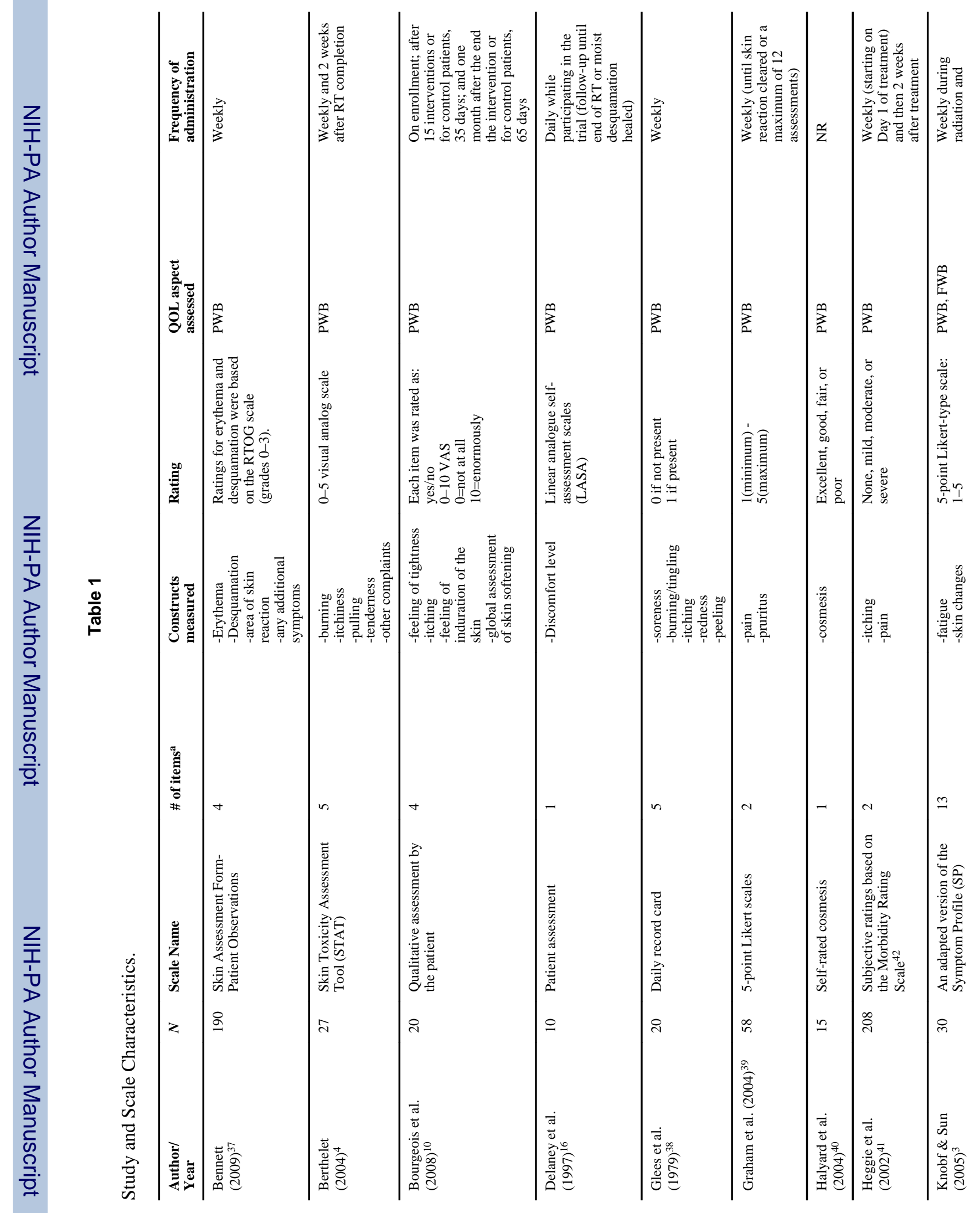


Schnur et al.

Page 12

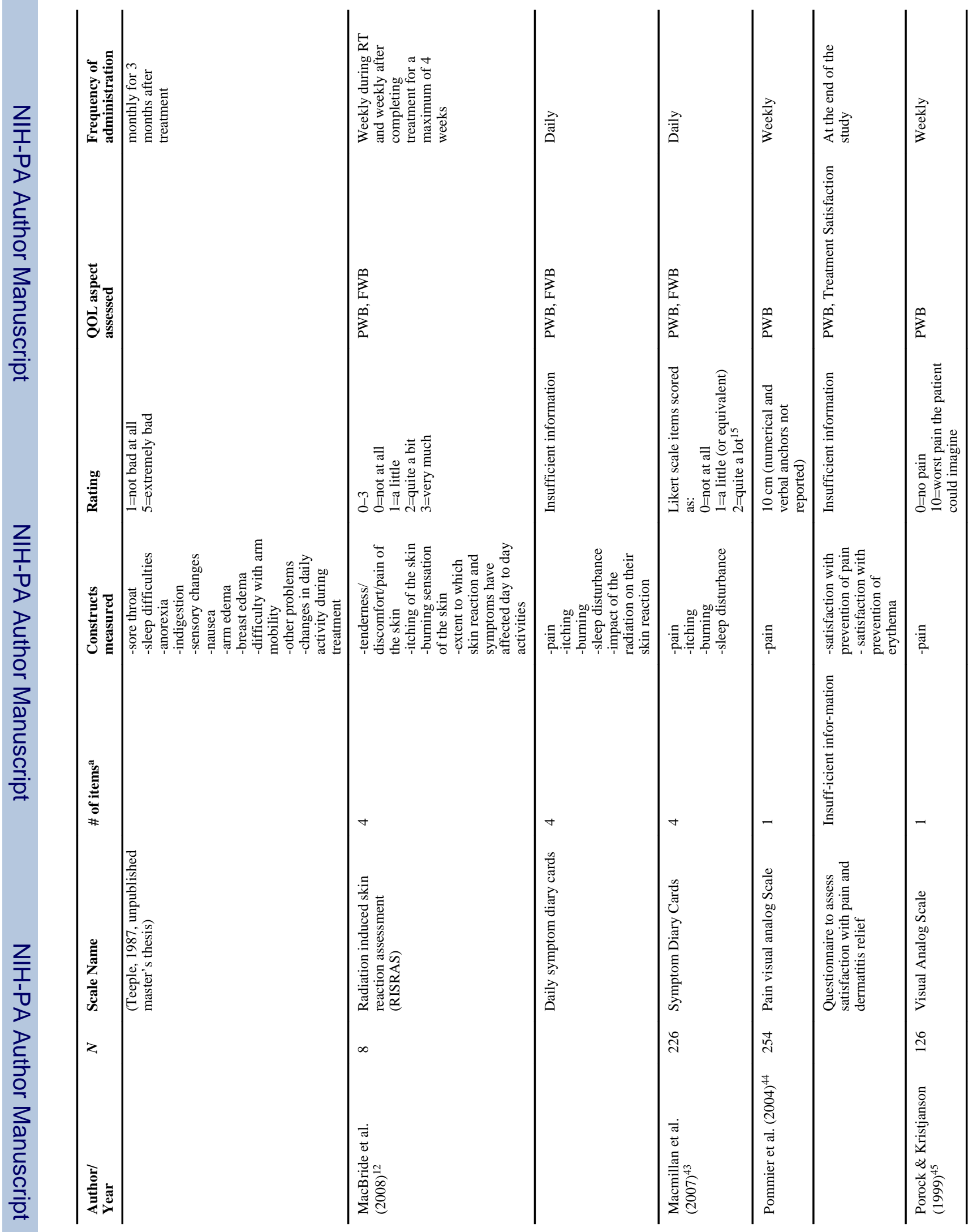

Am J Clin Oncol. Author manuscript; available in PMC 2013 July 30. 
Schnur et al.

Page 13

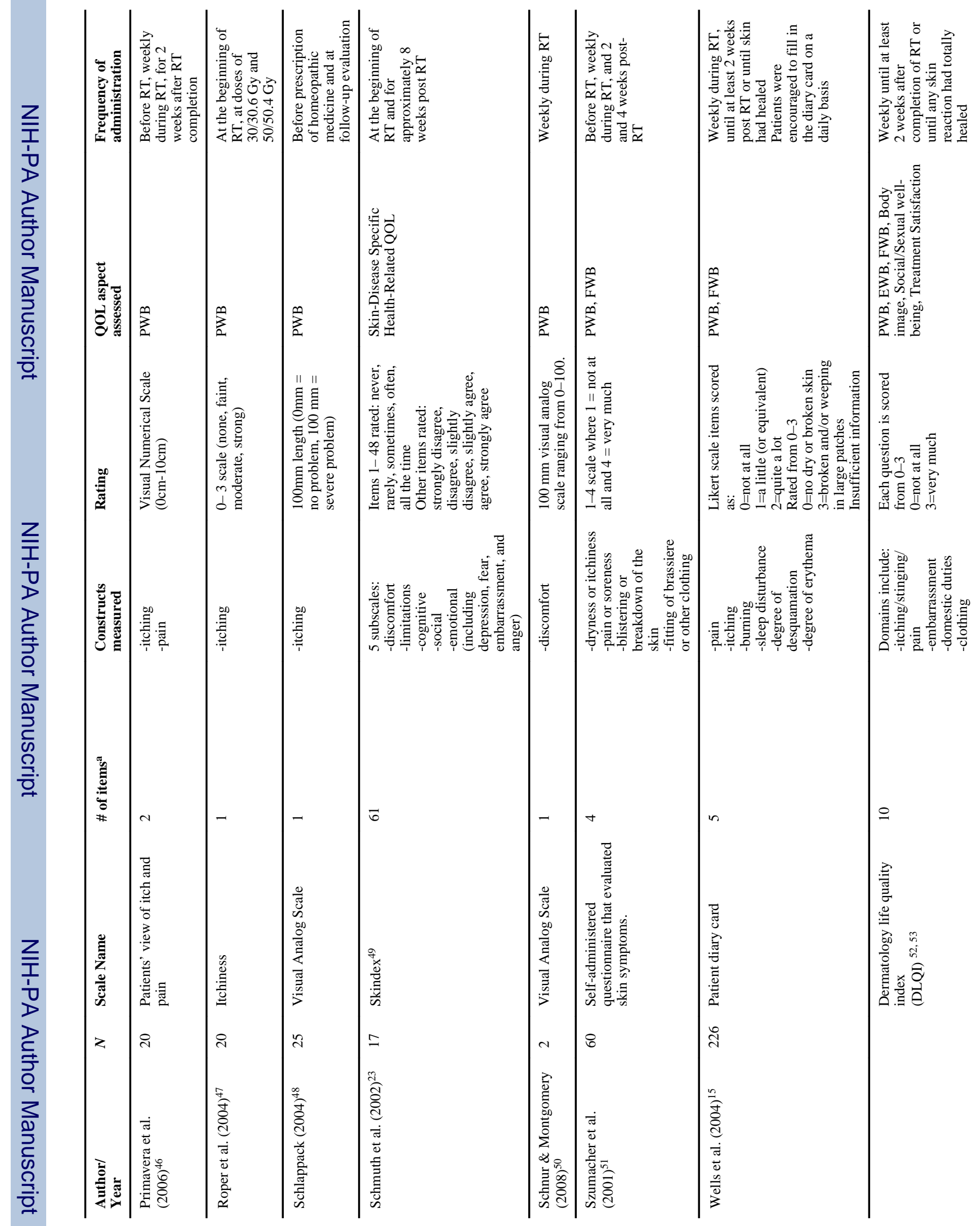

Am J Clin Oncol. Author manuscript; available in PMC 2013 July 30. 
Schnur et al.

Page 14

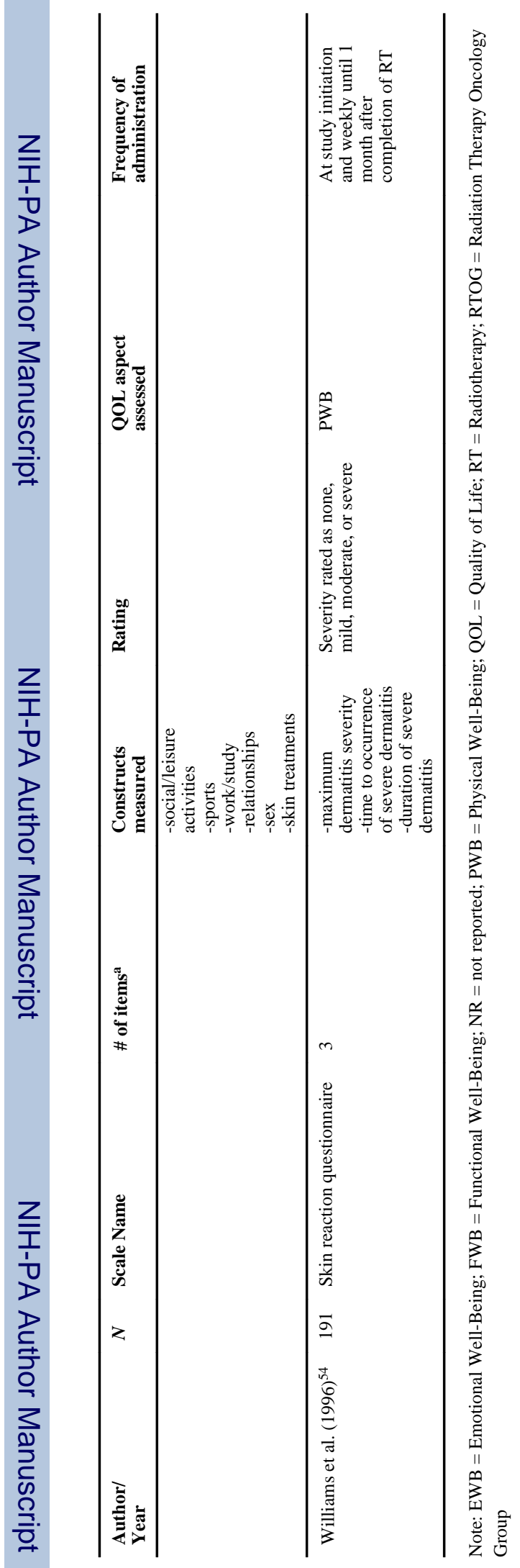

Am J Clin Oncol. Author manuscript; available in PMC 2013 July 30. 